\title{
Chemical and Biological Studies of Leaf Extract of Dendrophthoe falcata Linn.
}

\author{
Md. Rajdoula Rafe, Monira Ahsan, Choudhury Mahmood Hasan and \\ Mohammad Mehedi Masud
}

Phytochemical Research Laboratory, Department of Pharmaceutical Chemistry, Faculty of Pharmacy, University of Dhaka, Dhaka, Bangladesh

(Received: October 10, 2017; Accepted: November 20, 2017; Published (web): December 23, 2017)

\begin{abstract}
Dendrophthoe falcata (Family Loranthaceae) is used extensively in rural area as a component of ethno-medicine for the treatment of various diseases. In this study, the crude extracts and the fractions obtained from D. falcata were investigated for potential chemical constituents and some biological activities. For medicinal properties the antioxidant, brine shrimp lethality and thrombolytic activities have been investigated. The structures of the isolated three compounds were solved by extensive analyses of their high resolution ${ }^{1} \mathrm{HNMR}$ spectroscopic data. They were identified as Lupeol, 3- $\beta$-acetoxy-12-ene-11-one and $\beta$-sitosterol. For bioactivities, the petroleum ether, dichloromethane, chloroform and aqueous soluble fractions abbreviated as PESF, DCMSF, CSF and AQSF respectively. Brine shrimp lethality bioassay was used to evaluate potential cytotoxic activities, where all fractions showed significant activity with lower $\mathrm{LC}_{50}$. Most significant activity has been observed for methanol extract $\left(\mathrm{LC}_{50}=4.477 \mu \mathrm{g} / \mathrm{ml}\right)$. AQSF revealed maximum activity in DPPH free radical scavenging assay $\left(\mathrm{IC}_{50}=\right.$ of 43.49 $\mu \mathrm{g} / \mathrm{ml}$ ). In assay for thrombolytic activity, the methanol extract and its chloroform soluble fraction demonstrated significant efficacy with $32.65 \%$ and $32.36 \%$ clot lysis, respectively.
\end{abstract}

Key words: $\beta$-amyrin, lupeol, $3 \beta$-acetoxy-12-ene-11-one, $\beta$-sitosterol, antioxidant, cytotoxic, thrombolytic.

\section{INTRODUCTION}

Plants are considered as the most significant sources to discover and develop drugs which are effective and safer than the other currently available synthetic drugs. Due to the less side effects and better safety margin traditional and folk medicines are gaining popularity over modern therapy. 'Farolla' is Bengali name of the plant which is scientifically known as the Dendrophthoe falcata Linn. belongs to the hemiparasitic plant family Loranthaceae. It is used for long time as traditional medicine in India and Bangladesh to treat asthma, wounds, ulcer and pulmonary tuberculosis and it also included in the formulations of aphrodisiac, diuretic, astringent and narcotic traditional medicines. Previous study has

Correspondence to: Mohammad Mehedi Masud Email: mehedi33@du.ac.bd

Phone No. : +8801758064654

Dhaka Univ. J. Pharm. Sci. 16(2): 215-219, 2017 (December) shown that $D$. falcata is effective against wound by increasing the tensile strength of the affected area through contraction. ${ }^{1}$ Various chemical constituents have been reported from this plant such as $\beta$-amyrin acetate, $\beta$-sitostirol, stigmasterol, kaempferol, quercetin $^{2}$, quercetin-3-O-rhamnoside, rutin, myricetin, leucocyanidin and three biologically important cardiac glycosides such as strospeside, odoroside F and neritaloside. ${ }^{3}$ Another study reported that leaves extract possesses potent antioxidant activity by inhibiting various oxidizing agents like lipid peroxidation, reduced glutathione, and superoxide dismutase levels. ${ }^{4}$ In regular human metabolism different free radicals like hydroxyl, singlet oxygen, hydrogen peroxide, nitric oxide and superoxide radicals, are continuously generated. ${ }^{5,6}$ Especially, in living organisms, they play vital roles in cell signaling to inactivate relevant enzymes which consequently damage important cellular components. 
Antioxidants have been proved to resist the destruction of beta-cells ${ }^{7,8}$ as well as other cells and inhibit oxidation processes in the human body. ${ }^{9}$ Therefore, antioxidants are vital inhibitors of lipid peroxidation and act against oxidative damage or stress of living cells by natural defense mechanism. ${ }^{10}$ Another study with ethanolic extract of leaves of this plant has reported significant antioxidant activity. ${ }^{11}$ We have tried to explore the antioxidant activity by finding out the specific fraction/compound, which has maximum antioxidant activity. It was our main objective to find out any pharmacologically active compounds and to assess potential biological activities of $D$. falcata leaf extract.

\section{MATERIALS AND METHODS}

General experimental procedures. Nuclear magnetic resonance $\left({ }^{1} \mathrm{H}\right.$ NMR) spectra were recorded on ECA $(600 \mathrm{MHz})$ instrument indeuterated solvent $\left(\mathrm{CDCl}_{3}\right)$. Preliminary investigations of crude drugs were done by TLC on aluminum plates $(20 \times 20 \mathrm{~cm})$ pre-coated with silica gel $60 \mathrm{~F}_{254}$. The chromatogram developed by TLC and PTLC were sprayed with $1 \%$ vanillin-sulfuric acid reagent and then heated at $110^{\circ} \mathrm{C}$ for 5 minutes. All solvents used were of reagent grade.

Collection of plant. The leaves of $D$. falcata were collected from Sundarban area, Bangladesh in April, 2013 and the plant was verified and identified by an expert taxonomist of Bangladesh National Herbarium.

Extraction and isolation. The leaves were dried under sun light after washing properly with running water to eliminate other particles. Then the dried leaves were ground to a coarse powder by a grinding machine. The powdered plant material (800 gm) was taken in an amber colored bottle and soaked in methanol. The bottle with its contents was sealed and kept for 10 days with intermittent shaking and stirring. After that, the whole mixture was filtered, and the filtrate was concentrated with a rotary evaporator to obtain the crude extract. An aliquant crude extract was then fractionated with column chromatography by using a mixture of petroleum ether and ethyl acetate of increasing polarity. Fractions were screened by TLC and fractions showing similar feature were mixed together. Interesting fractions were further fractionated with gel permeation chromatography by using Sephadex LH-20, preparative TLC (stationary phase - silica gel $\mathrm{PF}_{254}$, mobile Phase: ethyl acetate-Toluene 2:98) of gel permeation chromatographic fractions 97-100 and 134-135 yielded two compound DF-1, DF-5 and DF6 respectively.

Design of biological investigations. The crude methanol extract was partitioned by modified Kupchan $^{12}$ method with petroleum ether, dichloromethane, chloroform and finally water.

Brine shrimp lethality bioassay. Brine shrimp lethality bioassay was used to assess the cytotoxic activity of methanol extract (ME) and its different partitionates i.e. petroleum ether (PESF), dichloromethane (DCMSF), chloroform (CSF) and aqueous soluble (AQSF) fraction according to the procedure of Meyer et al. ${ }^{13}$ These fractions were separately dissolved in DMSO. The test samples were then applied against Artemia salina in a 24 hour assay.

DPPH free radical scavenging activity. A method established by Choi et al. ${ }^{14}$ was used to determine the DPPH (2, 2-diphenyl-1-picrylhydrazyl) free radical scavenging activity. For this, $3 \mathrm{ml}$ of methanol solution of DPPH $(20 \mu \mathrm{g} / \mathrm{ml})$ was added into the test tube with $2 \mathrm{ml}$ (concentration ranging from 500.0 to $0.977 \mu \mathrm{g} / \mathrm{ml}$ ) of plant extract dissolved in methanol and the test tube was incubated for 30 minutes at room temperature for providing possible environment to complete the reaction process and absorbance was measured at $517 \mathrm{~nm}$.

Thrombolytic activity. During assay for thrombolytic activity, dry crude extract $(100 \mathrm{mg})$ along with various partitionates were suspended in distilled water $(10 \mathrm{ml})$ and kept overnight. Then the soluble supernatant was decanted and filtered. As positive control, $100 \mu \mathrm{l}$ of streptokinase (SK) and as negative non thrombolytic control, $100 \mu \mathrm{l}$ of distilled water were used. ${ }^{15}$ Difference obtained in weight 
taken before and after clot lysis was expressed as percentage of clot lysis as shown below:

$\%$ of clot lysis $=($ wt of released clot $/$ clot wt $) \times 100$

\section{RESULTS AND DISCUSSION}

Successive chromatographic separation and purification of leaf extract of D. falcata yielded several purified compounds from the leaf extract. Among them, the structures of three compounds were solved by extensive analyses of their high resolution ${ }^{1}$ HNMR spectroscopic data as well as by comparisons with related compounds. They are: lupeol, $3 \beta$-acetoxy-12-ene-11-one and $\beta$-sitosterol.

Lupeol (DF-1): White crystals; ${ }^{1} \mathrm{H}$ NMR (600 $\left.\mathrm{MHz}, \mathrm{CDCl}_{3}\right): \delta 4.67$ and $4.55(1 \mathrm{H}$, br s each), 1.68 (3H, s, H-30), 0.95 (3H, s, H-27), 1.03 (3H, s, H-26), $0.83(3 \mathrm{H}, \mathrm{s}, \mathrm{H}-25), 0.76(3 \mathrm{H}, \mathrm{s}, \mathrm{H}-24), 0.97$ (3H, s, H-23), 0.79 (3H, s, H-28), 2.36 (1H, m, H-19), 3.19 (1H, m, H-3).

$3 \beta$-acetoxy-olean-12-ene-11one (DF-5): Amorphous solid; ${ }^{1} \mathrm{H}$ NMR (600 $\left.\mathrm{MHz}, \mathrm{CDCl}_{3}\right)$ : $\delta 5.57$ (H-12), 1.33 (methyl), 1.17 (methyl), 1.14 (methyl), 0.86 (4 methyl), 0.83 (methyl), 2.03 (OAc), 4.51 (1H,m, H-3), 2.34 (1H, s, H-9).

$\beta$-sitosterol (DF-6): White crystal; The ${ }^{1} \mathrm{H}-\mathrm{NMR}$ spectrum $\left(600 \mathrm{MHz}, \mathrm{CDCl}_{3}\right) ; \delta_{\mathrm{H}} 3.50(1 \mathrm{H}, \mathrm{m}, \mathrm{H}-3)$, $\delta_{\mathrm{H}} 5.32(1 \mathrm{H}, \mathrm{m}, \mathrm{H}-6), \delta_{\mathrm{H}} 0.66(3 \mathrm{H}, \mathrm{s}, \mathrm{H}-13), \delta_{\mathrm{H}} 0.99$ $(3 \mathrm{H}, \mathrm{s}, \mathrm{H}-10), \delta_{\mathrm{H}} 0.84(1 \mathrm{H}, \mathrm{d}, \mathrm{H}-25), \delta_{\mathrm{H}} 0.82(1 \mathrm{H}, \mathrm{d}$, $\mathrm{H}-25), \delta_{\mathrm{H}} 0.90(1 \mathrm{H}, \mathrm{d}, \mathrm{H}-20), \delta_{\mathrm{H}} 0.86(J=7.5 \mathrm{~Hz}, \mathrm{t}$, $\mathrm{H}-28)$.

The ${ }^{1} \mathrm{H}$ NMR $\left(600 \mathrm{MHz}, \mathrm{CDCl}_{3}\right)$ spectrum $(1 \mathrm{H}$, dd, J-10.8, 5.4 Hz, H-3) of compound DF-1 displayed two olefinic protons at $\delta 4.67$ and $4.55(1 \mathrm{H}$, br. s each), a vinylic methyl at 1.68 and six tertiary methyl singlet at $0.95,1.03,0.83,0.76,0.97$ and 0.79 . The mulitplet of one proton intensity at $\delta 2.36$ was assigned to H-19. Moreover, the spectrum revealed signal at $\delta 3.19$ attributable to $\mathrm{H}-3$. On this basis, DF1 indicates the presence of lupeol. ${ }^{16}$

The ${ }^{1} \mathrm{H}$ NMR (600 MHz, $\mathrm{CDCl}_{3}$ ) spectrum of compound DF-5 displayed a sharp singlet at $\delta 5.57$ attributable to the olefinic proton (H-12) and eight tertiary methyl groups at $\delta 1.33,1.17,1.14,0.86$ (4 methyl) and 0.83 indicating triterpinoid skeleton. The spectrum further showed an acetyl methyl at $\delta 2.03$ and a multiplet at 4.51 assigned to $\mathrm{H}-3$ bonded to esterified carbon H-9 signal appeared as singlet at $\delta 2.34$. Based on the above evidence the structure of this compound was thus established as $3 \beta$-acetoxyolean-12-ene-11one. The ${ }^{1} \mathrm{H}$ NMR data of the compound was not available. However, it was found to be in close agreement with those of $3 \beta$-hydroxy11-oxo-olean-12-enyl palmitate. ${ }^{17}$

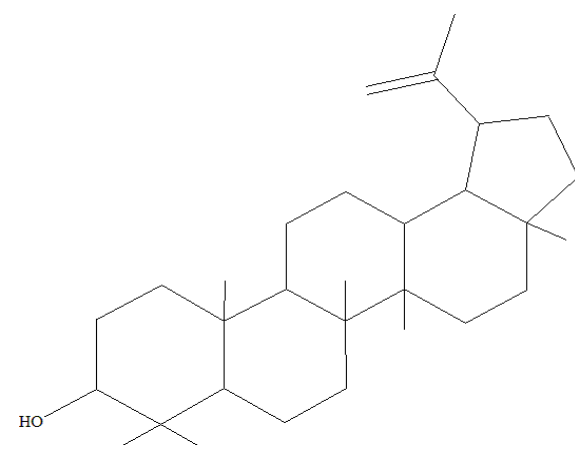

Lupeol

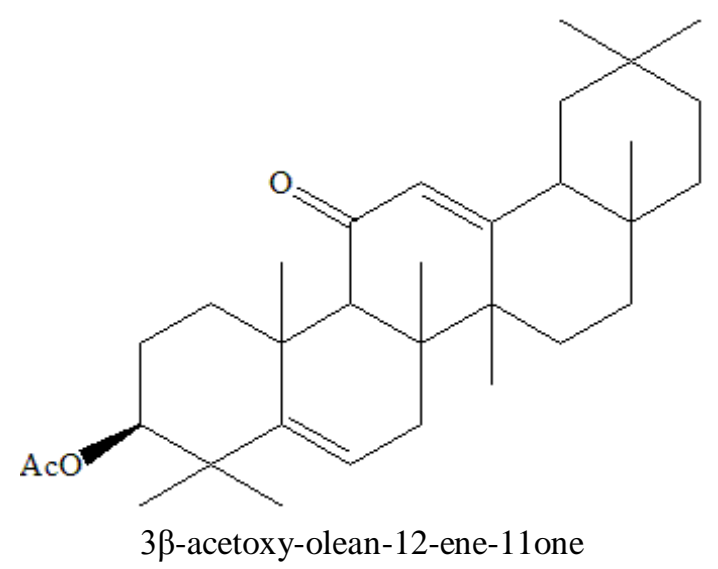

The ${ }^{1} \mathrm{H}$ NMR spectrum $\left(600 \mathrm{MHz}, \mathrm{CDCl}_{3}\right.$ ) of DF-6 revealed a one-proton multiplet at $\delta 3.50$, the position and multiplicity of which was indicative of C-3 protons (H-3) of the steroidal nucleus. The typical signal for H-6 of the steroidal skeleton was evident from a multiplet of one proton intensity at $\delta$ 5.32. The ${ }^{1} \mathrm{H}-\mathrm{NMR}$ spectrum also displayed signals at $\delta 0.66$ and $\delta 0.99$ ( $3 \mathrm{H}$ each) assignable to two tertiary methyl groups at $\mathrm{C}-13$ and $\mathrm{C}-10$ respectively. The ${ }^{1} \mathrm{H}-\mathrm{NMR}$ spectrum showed two doublet centered at $\delta$ 
$0.84(J=7.5 \mathrm{~Hz})$ and 0.82 which could be attributed to two methyl groups at $\mathrm{C}-25$. The doublet at $\delta 0.90$ was suggestive of a methyl group at C-20. On the other hand, the triplet at $\delta 0.86(J=7.5 \mathrm{~Hz})$ could be assigned to the primary methyl group attached to C28. The spectral features are in close agreement to those reported for $\beta$-sitosterol Jahan et al. ${ }^{18}$ Therefore, DF- 6 was identified as $\beta$-sitosterol.

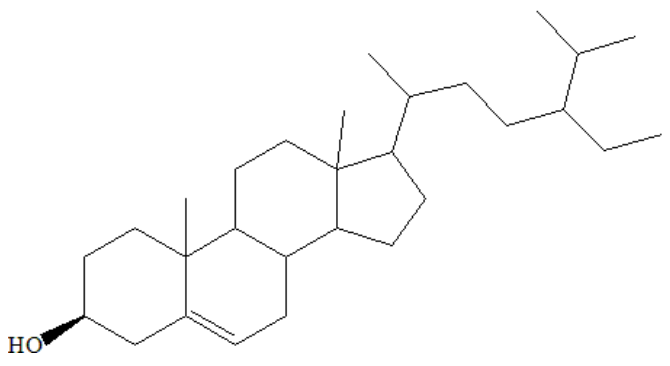

$\beta$-sitosterol

Compounds DF-1, Df-5 and DF-6 were readily identified as lupeol, 3- $\beta$-acetoxy-olean-12-ene-11one and $\beta$-sitosterol by careful analysis of their high resolution ${ }^{1} \mathrm{H}$ NMR spectral data as well as by comparison with published values. ${ }^{16-18}$

Different partitionates i.e. petroleum ether (PESF), dichloromethane (DCMSF), chloroform (CSF) and aqueous soluble fractions (AQSF) were tested for brine shrimp lethality according to the procedure of Meyer et al. ${ }^{13}$. In brine shrimp lethality bioassay, vincristine sulfate (VS) was used as positive control and the $\mathrm{LC}_{50}$ was found $0.394 \mu \mathrm{g} / \mathrm{ml}$ for VS. Among the extractives the crude extract demonstrated most significant cytotoxic activity which was evident from the $\mathrm{LC}_{50}$ value of 4.477 $\mu \mathrm{g} / \mathrm{ml}$ (Table 1).

In table 1, the free radical scavenging capacity of crude extract and various fractions showed significant activity as compared to ASA. The $\mathrm{IC}_{50}$ of ASA, ME, PESF, CSF and AQSF were $43.04 \pm 1.42$ $\mu \mathrm{g} / \mathrm{ml}, 305.00 \pm 4.51 \mu \mathrm{g} / \mathrm{ml}, 136.52 \pm 3.55 \mu \mathrm{g} / \mathrm{ml}$, $245.80 \pm 3.45 \mu \mathrm{g} / \mathrm{ml}$, and $43.49 \pm 1.12 \mu \mathrm{g} / \mathrm{ml}$, respectively (Table 1).

In order to get cardioprotective drugs from natural sources, the crude extracts and fractions obtained from $D$. falcata were assessed for thrombolytic activity using $100 \mu \mathrm{g}$ streptokinase (SK) as positive control (30,000 I.U). In this study, the petroleum soluble fraction (PESF) of $D$. falcata demonstrated highest thrombolytic activity (43.50\%) as shown in table 1 . However, the other partitionates of methanol extract of D. falcata such as dichloromethane (DCMSF), chloroform (CSF) and aqueous (AQSF) soluble fractions showed mild thrombolytic activity.

Table 1. Results of antioxidant, brine shrimp lethality and thrombolytic activities of crude extract and different fractions of $D$. falcata.

\begin{tabular}{lccc}
\hline Name of fractions & $\begin{array}{c}\text { Antioxidant activity } \\
\left(\mathrm{IC}_{50} \mu \mathrm{g} / \mathrm{ml}\right)\end{array}$ & $\begin{array}{c}\text { Brine shrimp lethality bioassay } \\
\left(\mathrm{LC}_{50} \mu \mathrm{g} / \mathrm{ml}\right)\end{array}$ & $\begin{array}{c}\text { Thrombolytic activity } \\
(\% \text { of clot lysis })\end{array}$ \\
\hline ME & $305.00 \pm 4.51$ & $4.477 \pm 0.83$ & $32.65 \pm 3.12$ \\
PESF & $136.52 \pm 3.55$ & $8.041 \pm 1.01$ & $43.50 \pm 4.02$ \\
DCMSF & $202.60 \pm 2.79$ & $69.098 \pm 1.78$ & $17.11 \pm 0.89$ \\
CSF & $245.80 \pm 3.45$ & $14.041 \pm 1.12$ & $32.36 \pm 1.83$ \\
AQSF & $43.49 \pm 1.12$ & $9.281 \pm 1.22$ & $11.24 \pm 1.16$ \\
ASA & $43.04 \pm 1.42$ & - & - \\
VS & - & $0.394 \pm 0.02$ & - \\
SK & - & - & $63.11 \pm 2.28$ \\
Blank & - & - & $5.78 \pm 0.95$ \\
\hline
\end{tabular}

Values are calculated from triplicate experiments and represented as mean $\pm \mathrm{STD}$. ME $=$ methanol extract, $\mathrm{PESF}=$ petroleum ether soluble fraction, $\mathrm{DCMSF}=$ dichloromethane soluble fraction, $\mathrm{CSF}=$ chloroform soluble fraction, $\mathrm{AQSF}=$ aqueous soluble fraction, $\mathrm{ASA}=\mathrm{ascorbic}$ acid soluble fraction, $\mathrm{VS}=$ vincristine sulphate, $\mathrm{SK}=$ streptokinase. 


\section{CONCLUSIONS}

The methanolic extract of the leaves of $D$. falcata (Family-Loranthaceae) was investigated for isolation of secondary metabolites and determination of bioactivities of this plant. Successive chromatographic separation and purification yielded a total of three compounds. From the biological investigations, it is proved that, the extractives of $D$. falcata showed significant antioxidant, cytotoxic and thrombolytic activities. However, further, studies are required to isolate more bioactive compounds responsible for the activities. The bioactivities shown by the extractives of $D$. falcata rationalize the traditional uses of this plant in various diseases.

\section{Competing interests}

The authors declare that they have no competing interests.

\section{REFERENCES}

1. Chopra, R.N., Nayar, S.L. and Chopra, I.C. 1956. Glossary of Indian medicinal plants. New Delhi. C SIR.

2. Ramchandran A.G. and Krishanakumary, P. 1990. Flavonoids of Dendrophthoe falcata Etting growing on different host plants. Ind. J. Chem. 29, 584-585.

3. Sinoriya, P.O.O.J.A., Sharma, V.I.R.E.N.D.R.A. and Sinoriya, A.R.T.I. 2011. A review on Dendrophthoe falcata (Linn. F.). Asian J. Pharm. Clin. Res. 4, 1-5.

4. Pattanayak, S.P. and Sunita, P., 2008. Wound healing, antimicrobial and antioxidant potential of Dendrophthoefalcata (Lf) Ettingsh. J. Ethnopharmacol. 120, 241-247.

5. Aruoma, O.I. and Cuppett, S.L. eds. 1997. Antioxidant methodology: in vivo and in vitro concepts. The American Oil Chemists Society.

6. Cavas, L. and Yurdakoc, K. 2005. An investigation on the antioxidant status of the invasive alga Caulerpa racemosa var. cylindracea (Sonder) Verlaque, Huisman, et Boudouresque (Caulerpales, Chlorophyta). J. Exp. Marine Biol. Ecol. 325, 189-200.

7. Slonim, A.E., Surber, M.L., Page, D.L., Sharp, R.A. and Burr, I.M. 1983. Modification of chemically induced diabetes in rats by vitamin E. Supplementation minimizes and depletion enhances development of diabetes. J. Clin. Investig. 71, 1282.
8. Murthy, V.K., Shipp, J.C., Hanson, C. and Shipp, D.M. 1992. Delayed onset and decreased incidence of diabetes in BB rats fed free radical scavengers. Diabetes Res. Clin. Prac. 18, 1116.

9. Diaz, M.N., Frei, B., Vita, J.A. and Keaney, Jr, J.F. 1997. Antioxidants and atherosclerotic heart disease. New England J. Med. 337, 408-416.

10. Halliwell, B. 1992. Reactive oxygen species and the central nervous system. J. Neuro Chem. 59, 1609-1623.

11. Hasan, M.S., Ahmed, M.I., Mondal, S., Masud, M.M., Sadhu, S.K., Ishibashi, M. and Uddin, S.J. 2006. Antioxidant, antinociceptive activity and general toxicity study of Dendrophthoe falcata and isolation of quercitrin as the major component. Orient. Pharm. Expe. Med. 6, 355-360.

12. Kupchan, S.M., Uchida, I., Branfman, A.R., Dailey, R.G. and Fei, B.Y. 1976. Antileukemic principles isolated from Euphorbiaceae plants. Sci. 191, 571-572.

13. Meyer, B.N., Ferrigni, N.R., Putnam, J.E., Jacobsen, L.B., Nichols, D.J. and McLaughlin, J.L. 1982. Brine shrimp: a convenient general bioassay for active plant constituents. Planta. 45, 31-34.

14. Meyer, B.N., Ferrigni, N.R., Putnam, J.E., Jacobsen, L.B., Nichols, D.J. and McLaughlin, J.L., 1982. Brine shrimp: a convenient general bioassay for active plant constituents. Planta Med. 45, 31-34.

15. Prasad, S., Kashyap, R.S., Deopujari, J.Y., Purohit, H.J., Taori, G.M. and Daginawala, H.F. 2007. Effect of Fagonia arabica (Dhamasa) on in vitro thrombolysis. BMC Complementary and Alternative Med. 7, 36.

16. Aratanechemuge, Y., Hibasami, H., Sanpin, K., Katsuzaki, H., Imai, K. and Komiya, T. 2004. Induction of apoptosis by lupeol isolated from mokumen (Gossampinus malabarica L. Merr) in human promyelotic leukemia HL-60 cells. Oncology Reports. 11, 289-292.

17. Barreiros, M.L., David, J.M., Pereira, P.A.D.P., Guedes, M.L. and David, J.P. 2002. Fatty acid esters of triterpenes from Erythroxylum passerinum. J. Brazilian Chem. Soc. 13, 669-673.

18. Jahan, I., Rahman, M., Rahman, M., Kaisar, M., Islam, M., Wahab, A. and Rashid, M. 2010. Chemical and biological investigations of Delonixregia (Bojer ex Hook.) Raf. Acta. Pharma. 60, 207-215. 